\title{
An empirical study on predicting user acceptance of e-shopping on the Web
}

\author{
Hung-Pin Shih* \\ Information Management Department, Hsuan Chuang University, Taiwan, ROC
}

Received 22 April 2002; received in revised form 31 October 2002; accepted 27 June 2003

\begin{abstract}
This study develops an extended model to predict consumer acceptance of electronic-shopping (e-shopping) based on the theory of reasoned action (TRA) and the technology acceptance model (TAM). Our model was tested using data collected from 212 questionnaires and analyzed using multiple regression. The results show that individual attitudes toward e-shopping are strongly and positively correlated with user acceptance. The empirical results confirmed that perceived ease of use of trading online (PEOUT) and perceived usefulness (PU) significantly determine individual attitudes toward e-shopping, as well as confirming the significant effect of perceived ease of use of the Web on PEOUT, which in turn affects PU. However, PU was not found to affect user acceptance significantly. Additionally, user satisfaction with the Internet/WWW and perceptions of information, system and service were shown to affect user acceptance significantly. Overall, the proposed model could be used to predict consumer willingness to shop on the Web.
\end{abstract}

(C) 2003 Elsevier B.V. All rights reserved.

Keywords: Technology acceptance model (TAM); Belief-attitude-intention-behavior relationship; Web; e-Shopping; User acceptance (UA)

\section{Introduction}

Electronic commerce generally refers to the sale and purchase of products and services on the Internet; consumer purchasing decisions mainly depend on individual evaluations of the value of products or services. Keeney [27] used a value proposition of e-commerce to represent customer evaluations, defining it as the net value of the benefits and costs associated with the transacted products or services in the processing of finding, ordering and receiving. With this, evaluations of outcomes about fundamental transaction objectives

\footnotetext{
*Tel.: +886-3-5302255/5225; fax: +886-3-5391252 E-mail address: hpshih@hcu.edu.tw (H.-P. Shih).
}

may influence buyers' decisions. For B2C e-commerce, electronic-shopping (e-shopping) involves intensive communication of information, and thus is an interactive behavior involving consumers and firms, conducted via the Internet or World Wide Web (WWW). Sellers can easily enter an e-market, reducing the costs of constructing and maintaining e-stores, especially of production, delivery, and storage of digital products or on-line services. From the perspective of consumers, an e-market is a trading center that supports the main e-shopping processes-from searching and requesting target products/services, through evaluating and selecting candidate products or services, to ordering, delivery, and final payment. The new channel of e-shopping thus has changed the relationship between consumers and firms. Thus, e-shopping is treated as a voluntary 
behavior in which consumers become more active and autonomous during a transaction [21].

\section{Literature review}

\subsection{Technology acceptance model}

According to the theory of reasoned action (TRA) model $[4,13]$, an individual's performance in a specific behavior is determined by his or her behavioral intentions, which themselves are jointly determined by individual attitudes and subjective norms. Attitudes are defined as the positive or negative feelings of an individual toward a specific behavior, and these are influenced by individual beliefs. An extended model of TRA, namely the theory of planned behavior (TPB) was derived by adding perceived behavioral control as a determinant of behavior [2,3]. TRA and TPB have been empirically validated, and both models are widely used for predicting or explaining cognitive and affective behavior using the beliefattitude-intention-behavior relationship in social psychology.

Building upon TRA, Davis [9] proposed the technology acceptance model (TAM) to explain and predict user acceptance of information systems (IS) or information technology (IT). Davis [11] defined perceived usefulness (PU) as, "the degree to which a person believes that using a particular system would enhance his or her job performance", and defined perceived ease of use (PEOU) as, "the degree to which a person believes that using a particular system would be free of effort". Within TAM, PU is a major factor, and PEOU is a secondary factor, in determining system usage. Moreover, Davis suggested that PEOU has a positive, indirect effect on system usage through PU. Empirical studies of TAM have shown that usage of IS is determined by user behavioral intentions, which themselves are jointly determined by user PU and attitudes toward using the IS, the last of which are jointly determined by user PU and PEOU. This also has a positive but indirect effect on attitude through PU [10]. Many IS studies have been conducted based on the TAM, since PU and PEOU are two general beliefs suited to predicting IS usage. All relevant empirical studies, such as the measurement of user acceptance of IT [1], and the self-reported usage of IS
[43], have supported the hypothesis of TAM that PU is directly related to IT/IS usage. Different from prior studies [8,17], Venkatesh and Davis [46] have shown that PEOU has a positive, direct effect on user acceptance of IT. However, no consistent conclusions have yet been reached about the effect of PEOU on IS/IT usage.

\subsection{Technological and organizational support}

Triandis [45] stated that facilitating conditions determine individual behavior. According to him, facilitating conditions represent the objective environmental factors that allow individuals to use an IS or IT. As verified in prior studies, organizational facilitating conditions affect individual use of PCs at work $[38,44]$, and technological facilitating conditions determine individual intentions to use the Internet/ WWW [7]. Moreover, organizational support not only influences PU and PEOU, but also affects the use of PCs [22,24]. Briefly, technological and organizational support can determine IT behavior.

\section{Extended model and research hypotheses}

Based on the belief-attitude-intention-behavior relationship in the TRA, this study proposes a model (Fig. 1) extending TAM to predict consumer e-shopping behavior. The model not only includes PEOU, $\mathrm{PU}$, attitudes toward e-shopping and user acceptance, but also adopts the Web environmental factors as the facilitating conditions of e-shopping, and includes perceived quality with respect to the websites by following Davis's [12] TAM involving system variables. Moreover, the empirical study tests the extended model using a questionnaire-based (as summarized in Appendix A) survey to explore the possible antecedent-consequence relationships.

\subsection{User acceptance of e-shopping}

When a consumer asks for product or service information, places an order, or pays over the Internet/ WWW, he or she will have perceptions of the target products or services, and will perform the transaction after evaluating its value in terms of benefits and costs. Perceptions of value assessments in e-shopping are 


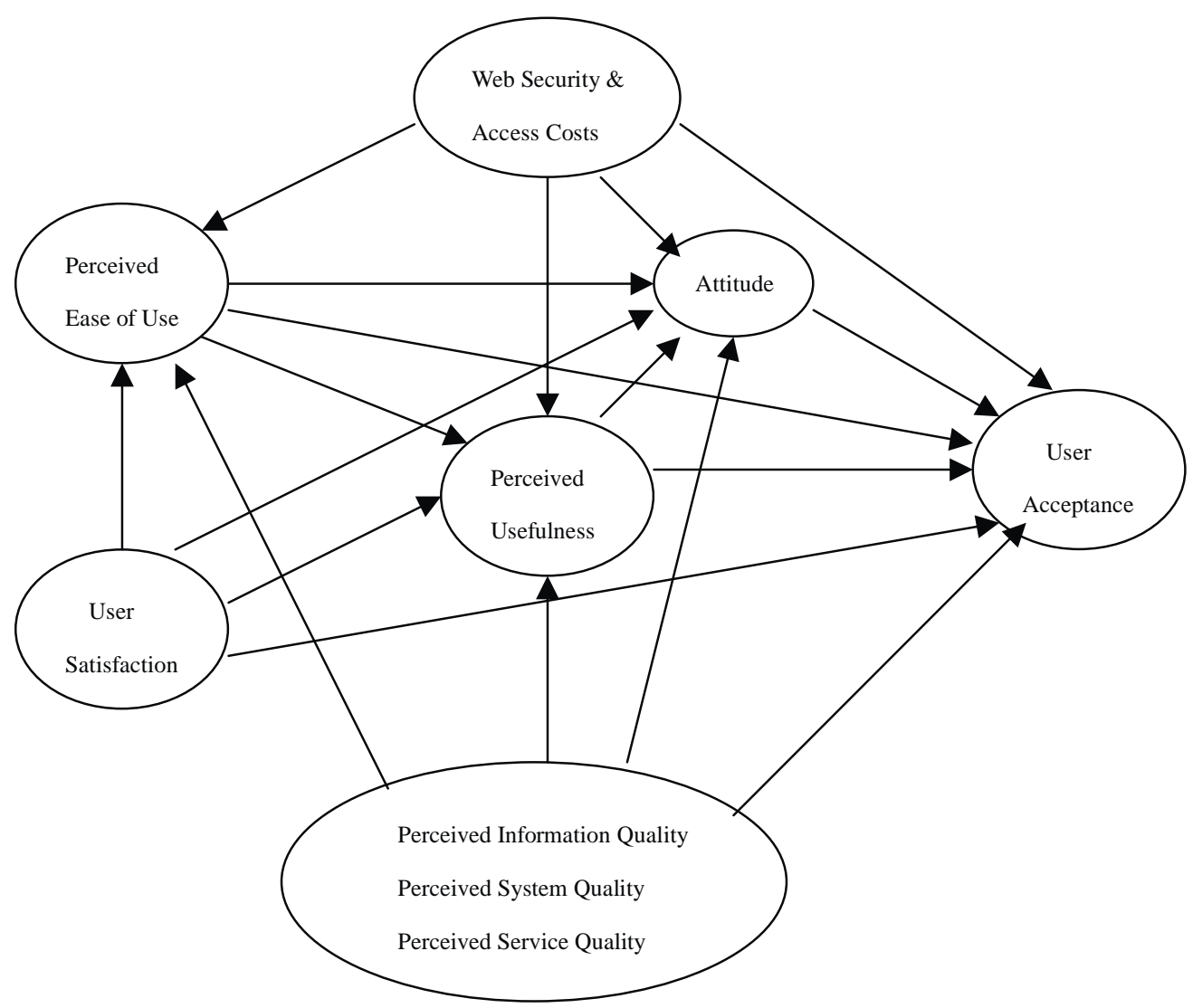

Fig. 1. Extended model based on TAM to predict e-shopping behavior.

termed user acceptance of e-shopping here. Based on the postulate of TRA, this study adopts user acceptance to represent individual behavioral intent towards e-shopping. Consequently, user acceptance is used as a surrogate for predicting actual consumer e-shopping behavior. Given the diversity of product types and delivery modes on the Internet/WWW [35], products and services were classified into physical products, such as PCs or mobile phones, digital products, such as software, and on-line services, such as hotel registration. From the perspective of e-shopping flow, this suggests that ordering, requesting post-purchase service, taking delivery, and paying on-line are the four main phases of a transaction between consumers and firms in e-shopping. Thus, user acceptance is split into user acceptance of products/services and user acceptance of on-line offerings. According to the relationship between behavioral intention and behavior in the
TRA, greater user acceptance implies increased willingness to e-shop.

\subsection{Attitude toward e-shopping}

According to the operational definition of TRA, individual attitudes toward a behavior are determined by individual affective beliefs about behavioral consequences and the evaluations of them. As proposed in TRA and TAM, attitude was expected to influence behavioral intention in using an IS. Thus, this study postulates that individual attitudes toward e-shopping affect user acceptance. As shown in Fig. 1, the following hypotheses about attitude are tested:

Hypothesis 1a. Individual attitudes toward e-shopping positively affect user acceptance of [physical products/digital products/on-line services]. 
Hypothesis 1b. Individual attitudes toward e-shopping positively affect user acceptance of [ordering/ post-purchase service/taking delivery/paying] on-line.

\subsection{Perceived usefulness}

According to the postulates and empirical results of TAM [33], the original PU is positively correlated with user attitudes toward an IS and its use. A website can be viewed as an IS, and provides information to its users. Therefore, consumers may perform e-shopping only if a website effectively assists them in completing transactions. We consider the PU to be perceived value (or perceived benefit), defining it as effectiveness of eshopping as perceived by the consumer. After revising Davis's definition of PU, the PU of e-shopping is defined as, the degree to which an individual believes that trading on the Web would enhance the effectiveness of his or her shopping. The following related hypotheses concerning the revised PU are:

Hypothesis 2a. Individual PU positively affects attitudes toward e-shopping.

Hypothesis 2b. Individual PU positively affects user acceptance of [physical products/digital products/online services].

Hypothesis 2c. Individual PU positively affects user acceptance of [ordering/post-purchase service/taking delivery/paying] on-line.

\subsection{Perceived ease of use of the Web and perceived ease of use of trading on-line}

Although Davis found that PEOU is positively correlated with system usage, he inferred that PEOU does not affect system usage if PU is under control. However, the positive relationship between PEOU and usage intentions was also suggested by Venkatesh and Davis. An analysis of the influential differences among prior studies shows that the effect of PEOU on IS/IT usage decreases with increasing user familiarity with the IS/IT. Restated, PEOU does not affect IT usage if the complexity of IT is very low. PEOU is therefore divided into two parts: PEOU of the Web (PEOUW) and PEOU of trading on-line (PEOUT). The former refers to ease of browsing, while the latter refers to ease of trading. The following hypotheses about PEOUW are tested here to explore the antecedent-consequence relationships in the extended model:

Hypothesis 3a. Individual PEOUW positively affects attitudes toward e-shopping.

Hypothesis 3b. Individual PEOUW positively affects PU.

Hypothesis 3c. Individual PEOUW positively affects PEOUT.

Hypothesis 3d. Individual PEOUW positively affects user acceptance of [physical products/digital products/ on-line services].

Hypothesis 3e. Individual PEOUW positively affects user acceptance of [ordering/post-purchase service/ taking delivery/paying] on-line.

Furthermore, the following hypotheses about PEOUT are tested:

Hypothesis 4a. Individual PEOUT positively affects attitudes toward e-shopping.

Hypothesis 4b. Individual PEOUT positively affects PU.

Hypothesis 4c. Individual PEOUT positively affects user acceptance of [physical products/digital products/ on-line services].

Hypothesis 4d. Individual PEOUT positively affects user acceptance of [ordering/post-purchase service/ taking delivery/paying] on-line.

\subsection{Web environment}

According to Triandis' model, facilitating conditions determine IS/IT usage behavior. Similarly, the Web environment is an important facilitating factor of e-shopping. Generally, most consumers evaluate the Web environment before performing e-shopping in an e-market. We select Web security and access costs as environmental constructs and measure them using individual perception. 


\subsubsection{Web security}

Consumers considering shopping on the Web are very concerned with payment risk, or personal risk [26], which mostly depends on security. In surveying attitudes toward Internet-based e-banking, Liao and Cheung [30] found that system security is a significant determinant of customer attitudes toward system use. Moreover, all measures of the system security were conducted on the security of accessing the Web. Thus, we test the following hypotheses:

Hypothesis 5a. Web security positively affects the PEOUW of e-shopping.

Hypothesis 5b. Web security positively affects the PEOUT of e-shopping.

Hypothesis 5c. Web security positively affects the PU of e-shopping.

Hypothesis 5d. Web security positively affects individual attitudes toward e-shopping.

Hypothesis 5e. Web security positively affects user acceptance of [physical products/digital products/online services].

Hypothesis 5f. Web security positively affects user acceptance of [ordering/post-purchase service/taking delivery/paying] on-line.

\subsubsection{Access costs}

The cost of accessing the Web is an important part of searching costs for consumers using the e-market [41]. We define access costs as including the network speed and the cost of accessing the Internet, both of which are easy to measure. The following hypotheses are therefore tested:

Hypothesis 6a. Access costs negatively affect the PEOUW of e-shopping.

Hypothesis 6b. Access costs negatively affect the PEOUT of e-shopping.

Hypothesis 6c. Access costs negatively affect the PU of e-shopping.
Hypothesis 6d. Access costs negatively affect individual attitudes toward e-shopping.

Hypothesis 6e. Access costs negatively affect user acceptance of [physical products/digital products/online services].

Hypothesis 6f. Access costs negatively affect user acceptance of [ordering/post-purchase service/taking delivery/paying] on-line.

\subsection{User satisfaction with the Internet/WWW}

Previous studies have indicated that user information satisfaction affects the effectiveness of IS $[16,18,25]$, system usage [6], as well as, directly or indirectly, affecting IS performance through IS usage [23]. Although Davis did not include user information satisfaction in his TAM, we revised it based on prior studies and define it as user satisfaction with the Internet/WWW. Regarding e-shopping, this study expected to derive the new relations among US, PU and PEOU. As consumers usually access the Internet/WWW to search for information before making purchases, this study infers that US directly and indirectly affects user acceptance of e-shopping:

Hypothesis 7a. Individual US positively affects PEOUW of e-shopping.

Hypothesis 7b. Individual US positively affects PEOUT of e-shopping.

Hypothesis 7c. Individual US positively affects PU of e-shopping.

Hypothesis 7d. Individual US positively affects attitudes toward e-shopping.

Hypothesis 7e. Individual US positively affects user acceptance of [physical products/digital products/ on-line services].

Hypothesis 7f. Individual US positively affects user acceptance of [ordering/post-purchase service/taking delivery/paying] on-line. 


\subsection{Perceived quality of e-shopping}

Consumers usually expect websites to support their shopping on the Web. For example, they may require accurate or available information on target products or services, a reliable website for accessing products or services, and good service. According to an expectancy-value approach, those perceptions of e-shopping are termed: perceived quality of information, system, and service. Moreover, these three constructs are the determinants of the success of websites [31]. Thus, this study postulates that perceived quality of information, system, and service can positively or negatively affect e-shopping behavior.

\subsubsection{Perceived information quality}

We considered information quality to be the output quality of IS, then used it to represent information characteristics. For example, Bailey and Pearson [5] developed scales for measuring IS satisfaction, including accuracy, precision, currency, timeliness, etc., to evaluate information quality. Previous studies frequently used information quality to measure IS performance $[32,34,40]$. Information quality is included in an assessment of the effect of Web use, especially on searching products/services in e-shopping. During e-shopping transactions, both consumers and firms communicate and coordinate by exchanging and sharing information via the Internet. Thus, perceived information quality is assessed using consumer perceptions of the quality of information on the Web. Perceived information quality is assumed to affect PEOUT, PU, attitudes toward e-shopping and user acceptance of e-shopping:

Hypothesis 8a. PIQ affects individual PEOUT.

Hypothesis 8b. PIQ affects individual PU.

Hypothesis 8c. PIQ affects individual attitudes toward e-shopping.

Hypothesis 8d. PIQ affects individual acceptance of [physical products/digital products/on-line services].

Hypothesis 8e. PIQ affects individual acceptance of [ordering/post-purchase service/taking delivery/paying] on-line.

\subsubsection{Perceived system quality}

System quality refers to the processing characteristics of an IS. Many studies thus have adopted system quality to measure IS performance [20,42]. The support functions of an IS are measured as "system quality". Thus, we consider consumer perceptions of the general and common support functions of information searching provided by websites as a measurement of perceived system quality. Accordingly, this extended model assumes that the perceived system quality of websites affects PEOUT, PU, attitudes toward e-shopping and user acceptance of e-shopping:

Hypothesis 9a. PSQ affects individual PEOUT.

Hypothesis 9b. PSQ affects individual PU.

Hypothesis 9c. PSQ affects individual attitudes toward e-shopping.

Hypothesis 9d. PSQ affects individual acceptance of [physical products/digital products/on-line services].

Hypothesis 9e. PSQ affects individual acceptance of [ordering/post-purchase service/taking delivery/ paying] on-line.

\subsubsection{Perceived service quality}

Parasuraman et al. [37] developed a 45-item instrument, namely SERVQUAL, to measure service quality in terms of tangibles, reliability, responsiveness, assurance and empathy, to assess customer expectations and perceptions of quality of service from both service and retailing organizations. In assessing the effectiveness of IS, many researchers have used SERVQUAL to measure IS service quality $[28,39,47]$. Their empirical results have shown that service quality is a determinant of IS success. According to Jarvenpaa and Todd's survey, many consumers said that they were dissatisfied with the quality of service provided by estores. Moreover, service quality was found to determine consumer willingness to e-shop [29]. When consumers initially access websites to search for products or services, service quality perceptions of websites may encourage or discourage them to make a purchase via the Web. In the extended model, perceived service quality of websites is assumed to 
affect PEOUT, PU, attitudes toward e-shopping and user acceptance of e-shopping:

Hypothesis 10a. PSvQ affects individual PEOUT.

Hypothesis 10b. PSvQ affects individual PU.

Hypothesis 10c. PSvQ affects individual attitudes toward e-shopping.

Hypothesis 10d. PSvQ affects individual acceptance of [physical products/digital products/on-line services].

Hypothesis 10e. PSvQ affects individual acceptance of [ordering/post-purchase service/taking delivery/ paying] on-line.

\section{Research methodology}

\subsection{Sample and procedure}

Many office workers access the Internet/WWW to search for information, and to communicate with other people or organizations. Office workers familiar with the Internet can be viewed as potential consumers since they have more chances to shop via the Internet than others. In the context of the Web, we selected office workers who have Internet/WWW experiences as subjects to investigate their perceptions and willingness to engage in e-shopping. All respondents, whose privacy was ensured, were asked to indicate the extent to which they agreed with the statements in the questionnaire.

Employees of eight small and medium-sized organizations in Taiwan, dealing in such diverse fields as PC manufacturing and sales, government projects, academia, avionics product manufacturing, information system development, asset insurance, car loans, and banking, participated in the study. For each organization a senior employee, with 3-10 years of work experience in their current position, was selected to distribute and collect the questionnaires. At each organization the survey was completed within a 3-week period. A total of 320 questionnaires were distributed to the organizations, and 242 were returned (a response rate of $75.6 \%$ ). As a result, 212 usable questionnaires were collected after eliminating 30 that included incomplete or conflicting replies (a net response rate of $66.2 \%$ ).

\subsection{Measurement}

Appendix A outlines the measurement scales used to operationalize research constructs. Respondents were asked to indicate agreement with each statement in a measure using a five-point Likert-type scale (1, strongly disagree; 2 , disagree; 3 , neutral; 4 , agree; 5 , strongly agree). The measures related to each construct then were assessed using respondent perceptions:

(1) Attitude

Following the definition in the TRA, attitude is measured in terms of individual preferences and interests via feelings and evaluations regarding eshopping outcomes.

(2) Web security and access costs

Web security comprises two measures, perceptions of firm trustworthiness and electronic security on the Web. Meanwhile, access costs include two measures: the evaluations of the cost of accessing the Web and network speed.

(3) PU

The objectives (25 of 43 fundamental objectives) of most consumers in e-commerce include "minimizing cost", "minimizing time to receive product", "maximizing convenience", and "minimizing time spent during a transaction"; these are related to the benefits and costs associated with e-shopping. That is, consumers prefer to evaluate the effectiveness of e-shopping based on its benefits and costs, rather than assessing the abstracted items of the original PU. Thus, our study measured the revised PU in terms of two important items: transaction cost and timeliness (the overall benefit of e-shopping).

(4) PEOUW and PEOUT

e-Shopping involves consumers and firms interacting via the Internet/WWW, and thus interactive processes of browsing, messaging and uploading/ downloading. Accordingly, this study focused on assessing the ease of its main processes, rather than its overall ease. Thus, measures of original PEOU were revised to meet this study. Since ease of accessing the Web differs from that of e-shopping procedures, PEOU is replaced with PEOUW and 
PEOUT. PEOUW was measured in terms of two items, ease of browsing and inquiry, while PEOUT was measured in terms of ease of ordering, receiving products and services, and paying via the Web.

(5) US

US is measured in terms of four composite items about Internet/WWW utilization: enhancement of quality of life, ability to learn, job performance, and domain knowledge as perceived by respondents in their current use of the Internet/ WWW.

(6) PIQ, PSQ and PSvQ

Our study developed composite measures of perceived quality by referring to items in prior studies. Some original items were revised to meet our study. In summary, our empirical study measured perceived quality of information, system, and service regarding customer expectations in e-shopping processes. Specifically, PIQ was measured in terms of five composite items: accuracy, completeness, understandability, timeliness, and availability of information provided by websites. Moreover, PSQ was measured in terms of three composite items: query and search supporting functions, and Web site reliability. Finally, PSvQ was measured in terms of four composite items: delivery timing, ease of returning merchandise, ease of payment, and protection of privacy.

(7) UA

UA was divided into user acceptance of products/services and on-line offerings to elucidate in detail behavioral intentions in e-shopping. The former was split into UA of physical products, digital products, and on-line services. The latter was split into UA of ordering, requesting postpurchase service, taking delivery, and paying online. Each UA was operationalized using a single measure in the questionnaire.

\section{Research results}

\subsection{Profile of the respondents}

As will be seen in Table 1, most respondents (over 98\%) had a college degree, or above, and their average age was 31.6 years. They had an average of 7.7 years of work experience, with 5.4 years at their current
Table 1

Profile of the respondents

\begin{tabular}{|c|c|}
\hline Characteristics & Statistics \\
\hline \multicolumn{2}{|l|}{ Gender } \\
\hline Male & $97(45.8 \%)$ \\
\hline Female & $115(54.2 \%)$ \\
\hline \multicolumn{2}{|l|}{ Age } \\
\hline Mean $=31.6$, S.D. $=6.5$ & Education \\
\hline High school & $4(1.9 \%)$ \\
\hline Junior college & $94(44.3 \%)$ \\
\hline University & $90(42.5 \%)$ \\
\hline Graduate school & $24(11.3 \%)$ \\
\hline \multicolumn{2}{|l|}{ Position (total $=204$, missing $=8$ ) } \\
\hline Administrative assistant/staff & $87(41.0 \%)$ \\
\hline Engineer & $40(18.9 \%)$ \\
\hline Manager & $29(13.7 \%)$ \\
\hline Planner & $21(9.9 \%)$ \\
\hline Researcher & $16(7.5 \%)$ \\
\hline Technician & $11(5.2 \%)$ \\
\hline \multicolumn{2}{|l|}{ Job } \\
\hline Work experience & $\begin{array}{l}\text { Mean }=7.7 \text { (years }) \\
\text { S.D. }=5.9(\text { total }=211)\end{array}$ \\
\hline Work experience in current company & $\begin{array}{l}\text { Mean }=5.4(\text { years }) \\
\text { S.D. }=5.1(\text { total }=206)\end{array}$ \\
\hline Internet/WWW experiences & $\begin{array}{l}\text { Mean }=4.3(\text { years }) \\
\text { S.D. }=2.3(\text { total }=212)\end{array}$ \\
\hline \multicolumn{2}{|l|}{ Internet/WWW use during work } \\
\hline Yes & $175(82.5 \%)$ \\
\hline No & $37(17.5 \%)$ \\
\hline \multicolumn{2}{|l|}{ e-Shopping experiences } \\
\hline Yes & $71(33.5 \%)$ \\
\hline No & $141(66.5 \%)$ \\
\hline
\end{tabular}

company. The jobs ranged widely, and included administration, IT/EE, management, planning, research, and technical support. Most respondents $(82.5 \%)$ had to use the Internet/WWW, and respondents had an average of 4.3 years of experience in using the Internet/WWW. However, just $33.5 \%$ had e-shopping experience. Generally, all respondents were familiar with the Internet/WWW. Overall, the sample group could be considered potential consumers to firms in e-marketing, and thus met the necessary conditions for taking this survey.

\subsection{Testing the extended model}

The constructs of the extended model were tested using convergent and discriminant validity to examine 
whether the constructs employed were adequate for predicting user acceptance of e-shopping.

\subsubsection{Convergent validity}

Fornell and Larcker [14] proposed three measures, including the item reliability of each measure, the composite (construct) reliability of each construct, and the average variance extracted for each construct, to assess the convergent validity of the measurements. The item reliability of a measure was assessed using its factor loading of the underlying construct. Hair et al. [19] suggested that a measure is significant if its factor loading greater than 0.5 ; this criterion was adopted to examine the item reliabilities of all measures. As shown in Table 2, the eigenvalues of all factors exceeded 1.0. Moreover, the percent of cumulative variance in these 10 factors was $77.9 \%$. Furthermore, the factor loadings of all measures on their underlying constructs exceeded 0.5 and the factor loadings of other constructs were below the 0.5 threshold.

Construct reliability was assessed using Cronbach's $\alpha$. Nunnally [36] suggested that a reliability of a construct between 0.6 and 0.8 is acceptable. As shown in Table 3, with the exception of the dependent variable with a single measure, the reliabilities of all other constructs are between 0.63 and 0.95 , thus passing the test of construct reliability.

Fornell and Larcker suggested that the average variance extracted from a construct should exceed 0.5. From Table 3, the average variance extracted from each construct exceeded 0.5. Overall, the convergent

Table 2

Principal component factor analysis with equamax rotation

\begin{tabular}{|c|c|c|c|c|c|c|c|c|c|c|}
\hline Measures & A & S & $\mathrm{AC}$ & PEOUW & PEOUT & $\mathrm{PU}$ & US & PIQ & PSQ & PSvQ \\
\hline A1 & 0.69 & 0.12 & -0.23 & 0.08 & 0.20 & 0.27 & 0.26 & 0.11 & 0.05 & 0.09 \\
\hline A2 & 0.86 & 0.20 & -0.05 & -0.03 & 0.07 & 0.24 & 0.00 & -0.01 & 0.05 & -0.12 \\
\hline $\mathrm{S} 1$ & 0.15 & 0.70 & 0.29 & 0.11 & 0.04 & 0.13 & -0.05 & -0.10 & 0.01 & 0.06 \\
\hline $\mathrm{S} 2$ & 0.07 & 0.88 & 0.08 & 0.06 & 0.05 & 0.03 & 0.03 & 0.04 & -0.07 & -0.02 \\
\hline $\mathrm{AC} 1$ & -0.15 & 0.18 & 0.84 & 0.01 & 0.03 & 0.08 & 0.10 & -0.05 & 0.00 & -0.06 \\
\hline $\mathrm{AC} 2$ & -0.01 & 0.15 & 0.86 & 0.00 & 0.02 & -0.03 & -0.03 & -0.06 & -0.03 & -0.03 \\
\hline PEOUW1 & 0.06 & 0.05 & -0.01 & 0.91 & 0.07 & 0.10 & 0.05 & -0.01 & 0.04 & 0.03 \\
\hline PEOUW2 & -0.03 & 0.10 & 0.02 & 0.86 & 0.22 & 0.06 & 0.10 & -0.02 & -0.01 & 0.01 \\
\hline PEOUT1 & 0.07 & 0.02 & -0.01 & 0.25 & 0.79 & 0.08 & 0.10 & 0.09 & 0.07 & 0.03 \\
\hline PEOUT2 & 0.41 & -0.12 & 0.24 & 0.18 & 0.65 & 0.08 & 0.00 & 0.02 & -0.08 & 0.14 \\
\hline PEOUT3 & 0.03 & 0.16 & -0.05 & 0.05 & 0.83 & 0.17 & 0.15 & -0.01 & 0.12 & -0.05 \\
\hline PU1 & 0.20 & -0.01 & -0.01 & 0.21 & 0.11 & 0.81 & 0.05 & 0.07 & 0.04 & -0.01 \\
\hline PU2 & 0.14 & 0.16 & 0.06 & -0.02 & 0.10 & 0.84 & -0.01 & -0.02 & 0.06 & 0.07 \\
\hline US1 & 0.09 & 0.02 & -0.06 & 0.03 & 0.16 & 0.14 & 0.84 & 0.02 & 0.08 & -0.01 \\
\hline US2 & 0.05 & 0.07 & -0.02 & 0.10 & 0.15 & 0.11 & 0.87 & 0.07 & 0.06 & 0.05 \\
\hline US3 & 0.38 & -0.09 & 0.12 & 0.09 & -0.04 & -0.14 & 0.68 & 0.14 & 0.06 & 0.14 \\
\hline US4 & 0.06 & -0.04 & 0.04 & 0.13 & 0.13 & -0.03 & 0.83 & 0.04 & -0.01 & 0.16 \\
\hline PIQ1 & 0.11 & 0.00 & -0.14 & -0.03 & 0.07 & 0.08 & 0.11 & 0.77 & 0.27 & 0.31 \\
\hline PIQ2 & 0.12 & -0.01 & -0.12 & 0.00 & 0.09 & -0.01 & 0.10 & 0.79 & 0.31 & 0.23 \\
\hline PIQ3 & 0.04 & -0.06 & -0.07 & 0.05 & 0.11 & 0.11 & 0.10 & 0.79 & 0.36 & 0.19 \\
\hline PIQ4 & 0.16 & -0.05 & -0.15 & -0.01 & 0.04 & 0.06 & 0.06 & 0.82 & 0.27 & 0.23 \\
\hline PIQ5 & 0.11 & -0.08 & -0.11 & -0.05 & 0.05 & 0.09 & 0.08 & 0.74 & 0.37 & 0.28 \\
\hline PSQ1 & 0.10 & 0.00 & -0.12 & -0.03 & 0.10 & 0.08 & 0.00 & 0.36 & 0.78 & 0.23 \\
\hline PSQ2 & 0.08 & -0.01 & -0.01 & 0.05 & 0.05 & 0.17 & 0.06 & 0.19 & 0.86 & 0.17 \\
\hline PSQ3 & 0.04 & -0.10 & -0.03 & 0.04 & 0.10 & 0.04 & 0.07 & 0.24 & 0.75 & 0.29 \\
\hline PSvQ1 & 0.18 & 0.12 & -0.17 & -0.02 & 0.10 & 0.08 & 0.09 & 0.22 & 0.37 & 0.66 \\
\hline PSvQ2 & 0.08 & 0.07 & -0.20 & -0.03 & 0.05 & 0.07 & 0.18 & 0.28 & 0.35 & 0.73 \\
\hline PSvQ3 & -0.04 & 0.12 & -0.17 & 0.06 & -0.06 & 0.08 & 0.00 & 0.22 & 0.28 & 0.76 \\
\hline PSvQ4 & 0.00 & -0.18 & 0.12 & 0.04 & 0.09 & 0.01 & 0.11 & 0.10 & 0.07 & 0.78 \\
\hline Eigenvalue & 1.78 & 1.55 & 1.89 & 1.77 & 1.99 & 1.70 & 2.84 & 3.54 & 2.82 & 2.72 \\
\hline Percent of variance & 6.15 & 5.33 & 6.50 & 6.11 & 6.86 & 5.86 & 9.79 & 12.21 & 9.72 & 9.38 \\
\hline
\end{tabular}


Table 3

Convergent validity test

\begin{tabular}{lll}
\hline Constructs & $\begin{array}{l}\text { Construct } \\
\text { reliability }^{\mathrm{a}}\end{array}$ & \begin{tabular}{l} 
Portion of variance $_{\text {extracted }^{\mathrm{b}}}$ \\
\hline A
\end{tabular} O.77 \\
S & 0.63 & 0.61 \\
AC & 0.77 & 0.63 \\
PEOUW & 0.79 & 0.72 \\
PEOUT & 0.74 & 0.78 \\
PU & 0.68 & 0.58 \\
US & 0.86 & 0.68 \\
PIQ & 0.95 & 0.65 \\
PSQ & 0.87 & 0.61 \\
PSvQ & 0.85 & 0.64 \\
UAPP & 1.00 & 0.54 \\
UADP & 1.00 & 1.00 \\
UAOS & 1.00 & 1.00 \\
UAO & 1.00 & 1.00 \\
UAPS & 1.00 & 1.00 \\
UAD & 1.00 & 1.00 \\
UAP & 1.00 & 1.00 \\
\hline
\end{tabular}

${ }^{\text {a }}$ Construct reliability is estimated using Cronbach's $\alpha$ coefficients.

${ }^{\mathrm{b}}$ Portion of variance extracted is estimated by computing, squared sum of factor loadings/number of factors of the underlying construct. validity test indicated that the proposed constructs of the extended model were adequate.

\subsubsection{Discriminant validity}

Discriminant validity is used to assess the extent to which constructs differ. Generally, a measure should correlate more highly with other measures of the same construct than with measures of other constructs. As suggested by Fornell et al. [15], the squared correlations between two different measures in any two constructs should be statistically lower than the variance shared by the measures of a construct.

Following these arguments regarding discriminant validity, we tested constructs rather than measures. Table 4 presents the results of the discriminant validity test. All shared variances between any two different constructs were less than the amount of variance extracted by one of the two constructs. Therefore, the constructs of the extended model exhibit adequate discriminant validity.

\subsection{Regression analysis of the extended model}

Our empirical study is an early piece of research in the theory generation phase, and thus multiple regression analysis was used to test the possible

Table 4

Discriminant validity test $\mathrm{t}^{\mathrm{a}}$

\begin{tabular}{|c|c|c|c|c|c|c|c|c|c|c|c|}
\hline Constructs & A & $\mathrm{S}$ & $\mathrm{AC}$ & PEOUW & PEOUT & PU & US & PIQ & PSQ & PSvQ & UA \\
\hline A & 0.610 & & & & & & & & & & \\
\hline $\mathrm{S}$ & 0.057 & 0.630 & & & & & & & & & \\
\hline $\mathrm{AC}$ & 0.014 & 0.097 & 0.720 & & & & & & & & \\
\hline PEOUW & 0.017 & 0.030 & 0.003 & 0.780 & & & & & & & \\
\hline PEOUT & 0.124 & 0.022 & 0.005 & 0.130 & 0.580 & & & & & & \\
\hline PU & 0.190 & 0.054 & 0.001 & 0.047 & 0.103 & 0.680 & & & & & \\
\hline US & 0.084 & 0.001 & 0.000 & 0.039 & 0.086 & 0.014 & 0.650 & & & & \\
\hline PIQ & 0.050 & 0.006 & 0.044 & 0.000 & 0.028 & 0.021 & 0.058 & 0.610 & & & \\
\hline PSQ & 0.033 & 0.001 & 0.015 & 0.003 & 0.035 & 0.042 & 0.033 & 0.458 & 0.640 & & \\
\hline PSvQ & 0.025 & 0.000 & 0.027 & 0.003 & 0.020 & 0.021 & 0.064 & 0.382 & 0.376 & 0.540 & \\
\hline UAPP & 0.331 & 0.032 & 0.007 & 0.023 & 0.032 & 0.067 & 0.031 & 0.066 & 0.016 & 0.004 & $<1.000^{\mathrm{b}}$ \\
\hline UADP & 0.356 & 0.020 & 0.009 & 0.031 & 0.042 & 0.102 & 0.099 & 0.086 & 0.080 & 0.013 & $<1.000$ \\
\hline UAOS & 0.151 & 0.015 & 0.040 & 0.048 & 0.037 & 0.068 & 0.155 & 0.061 & 0.056 & 0.069 & $<1.000$ \\
\hline UAO & 0.372 & 0.031 & 0.014 & 0.012 & 0.120 & 0.135 & 0.067 & 0.099 & 0.085 & 0.092 & $<1.000$ \\
\hline UAPS & 0.131 & 0.002 & 0.030 & 0.048 & 0.032 & 0.045 & 0.090 & 0.033 & 0.053 & 0.061 & $<1.000$ \\
\hline UAD & 0.224 & 0.054 & 0.013 & 0.036 & 0.040 & 0.097 & 0.034 & 0.050 & 0.065 & 0.031 & $<1.000$ \\
\hline UAP & 0.257 & 0.147 & 0.000 & 0.028 & 0.087 & 0.096 & 0.001 & 0.042 & 0.009 & 0.014 & $<1.000$ \\
\hline
\end{tabular}

${ }^{\text {a }}$ Diagonal elements represent the variance extracted, while the other matrix elements represent the shared variance.

${ }^{\mathrm{b}}$ The correlations between any two distinct UAs of \{UAPP, UADP, UAOS, UAO, UAPS, UAD, UAP $\}$ were lesser than 1.000. 
antecedent-consequence relationships in the extended model. The regression model was adequate, passing the normal distribution test, and the multicollinearity among the selected constructs was ignored after diagnosis.

\subsubsection{Predicting user acceptance of e-shopping}

5.3.1.1. User acceptance of physical products. As shown in Table 5, individual attitudes toward e-shopping and PIQ were found to have strong positive effects on user acceptance of physical products. Additionally, PSvQ negatively affected user acceptance of physical products. Overall, this regression model explained up to $35.4 \%$ of the variance in user acceptance of physical products.

\subsubsection{User acceptance of digital products. Table 5} shows that individual attitudes toward e-shopping to be strong and positive in affected user acceptance of digital products. Additionally, US, PIQ and PSQ were found to have significant positive effects on user acceptance of digital products. However, PSvQ significantly and negatively affected user acceptance of digital products. This regression model explained up to $42.2 \%$ of the variance in user acceptance of digital products.
5.3.1.3. User acceptance of on-line services. Table 5 shows that individual attitudes toward e-shopping and US significantly and positively affected user acceptance of on-line services. In contrast, access costs were found to significantly and negatively affect user acceptance of on-line services. This regression model explained $28.3 \%$ of the variance in user acceptance of on-line services.

\subsubsection{Predicting user acceptance of on-line offerings}

5.3.2.1. Ordering. Table 6 shows that only individual attitudes toward e-shopping was found to have a significant and strong positive effect on user acceptance of ordering on-line. This regression model explained up to $41.8 \%$ of the variance in user acceptance of ordering on-line.

5.3.2.2. Post-purchase service. From Table 6, individual attitudes toward e-shopping, PEOUW and US significantly and positively affected user acceptance of on-line post-purchase service. Overall, this regression model explained $20.5 \%$ of the variance in user acceptance of on-line post-purchase service.

5.3.2.3. Delivery. In surveying the delivery of digital products or on-line services, Table 6 presents the strong

Table 5

Regression results on predicting user acceptance of physical/digital products and on-line services

\begin{tabular}{|c|c|c|c|c|c|c|}
\hline \multirow[t]{3}{*}{ Independent variables } & \multicolumn{6}{|c|}{ Dependent variables: user acceptance } \\
\hline & \multicolumn{2}{|c|}{ Physical products } & \multicolumn{2}{|c|}{ Digital products } & \multicolumn{2}{|c|}{ On-line services } \\
\hline & $\beta_{\mathrm{S}}{ }^{\mathrm{a}}$ & $P$-value & $\beta_{\mathrm{S}}$ & $P$-value & $\beta_{\mathrm{S}}$ & $P$-value \\
\hline A & $0.540^{* * * *}$ & 0.000 & $0.508^{* * *}$ & 0.000 & $0.198^{* *}$ & 0.006 \\
\hline S & 0.069 & 0.269 & 0.028 & 0.631 & 0.096 & 0.146 \\
\hline $\mathrm{AC}$ & -0.013 & 0.838 & -0.026 & 0.651 & $-0.197^{* *}$ & 0.003 \\
\hline PEOUW & 0.105 & 0.087 & 0.104 & 0.072 & 0.125 & 0.052 \\
\hline PEOUT & -0.073 & 0.263 & -0.106 & 0.086 & -0.060 & 0.382 \\
\hline PU & 0.002 & 0.981 & 0.057 & 0.354 & 0.092 & 0.180 \\
\hline US & 0.002 & 0.969 & $0.155^{* *}$ & 0.008 & $0.289^{* * *}$ & 0.000 \\
\hline PIQ & $0.293^{* * *}$ & 0.000 & $0.158^{*}$ & 0.044 & 0.009 & 0.916 \\
\hline PSQ & -0.059 & 0.468 & $0.197^{*}$ & 0.011 & 0.064 & 0.451 \\
\hline PSvQ & $-0.169^{*}$ & 0.027 & $-0.229^{* *}$ & 0.002 & 0.069 & 0.388 \\
\hline Adjusted $R^{2}$ & 0.354 & & 0.422 & & 0.283 & \\
\hline
\end{tabular}

${ }^{\text {a }}$ Standardized $\beta$ coefficient.

* 0.05 significance level.

** 0.01 significance level.

**** 0.001 significance level. 
Table 6

Regression results on predicting user acceptance of on-line offerings

\begin{tabular}{|c|c|c|c|c|c|c|c|c|}
\hline \multirow{3}{*}{$\begin{array}{l}\text { Independent } \\
\text { variables }\end{array}$} & \multicolumn{8}{|c|}{ Dependent variables: user acceptance } \\
\hline & \multicolumn{2}{|c|}{ Ordering on-line } & \multicolumn{2}{|c|}{ Post-purchase service on-line } & \multicolumn{2}{|c|}{ Take delivery on-line } & \multicolumn{2}{|l|}{ Pay on-line } \\
\hline & $\beta_{\mathrm{S}}{ }^{\mathrm{a}}$ & $P$-value & $\beta_{\mathrm{S}}$ & $P$-value & $\beta_{\mathrm{S}}$ & $P$-value & $\beta_{\mathrm{S}}$ & $P$-value \\
\hline A & $0.468^{* * *}$ & 0.000 & $0.258^{* *}$ & 0.001 & $0.347^{* * *}$ & 0.000 & $0.388^{* * *}$ & 0.000 \\
\hline S & 0.055 & 0.354 & -0.022 & 0.753 & $0.160^{*}$ & 0.017 & $0.286^{* * *}$ & 0.000 \\
\hline $\mathrm{AC}$ & -0.052 & 0.376 & -0.133 & 0.052 & -0.110 & 0.095 & -0.037 & 0.544 \\
\hline PEOUW & -0.035 & 0.545 & $0.155^{*}$ & 0.023 & 0.109 & 0.093 & 0.055 & 0.366 \\
\hline PEOUT & 0.119 & 0.056 & -0.041 & 0.567 & -0.043 & 0.535 & 0.121 & 0.063 \\
\hline $\mathrm{PU}$ & 0.082 & 0.184 & 0.041 & 0.568 & 0.079 & 0.250 & 0.037 & 0.560 \\
\hline US & 0.032 & 0.583 & $0.179^{* *}$ & 0.009 & 0.036 & 0.586 & $-0.169^{* *}$ & 0.006 \\
\hline PIQ & 0.061 & 0.433 & -0.109 & 0.234 & 0.035 & 0.688 & $0.239^{* *}$ & 0.004 \\
\hline PSQ & 0.045 & 0.557 & 0.125 & 0.166 & 0.165 & 0.057 & -0.133 & 0.100 \\
\hline PSvQ & 0.119 & 0.102 & 0.121 & 0.152 & -0.043 & 0.597 & -0.002 & 0.979 \\
\hline Adjusted $R^{2}$ & 0.418 & & 0.205 & & 0.265 & & 0.364 & \\
\hline
\end{tabular}

${ }^{\text {a }}$ Standardized $\beta$ coefficient.

* 0.05 significance level.

*** 0.01 significance level.

*** 0.001 significance level.

and significantly positive effects of individual attitudes toward e-shopping on user acceptance of taking delivery on-line. Additionally, Web security was found to have a significant positive effect on user acceptance of taking delivery on-line. Overall, this regression model explained $26.5 \%$ of the variance in user acceptance of taking delivery on-line.

5.3.2.4. Pay. From Table 6, individual attitudes toward e-shopping, Web security and PIQ were found to have significant positive effects on user acceptance of paying on-line. However, US was found to have a significant negative effect on user acceptance of paying on-line. Consequently, this regression model explained up to $36.4 \%$ of the variance in user acceptance of paying on-line.

\subsubsection{Explaining attitude}

As shown in Table 7, Web security, PEOUT, PU and US significantly and positively affected individual attitudes toward e-shopping (supporting Hypotheses $5 \mathrm{~d}, 4 \mathrm{a}, 2 \mathrm{a}$ and $7 \mathrm{~d}$, respectively). On the contrary, access costs significantly and negatively influenced individual attitudes toward e-shopping (supporting Hypothesis 6d). This regression model explained $31.3 \%$ of the variance in individual attitudes toward e-shopping.

\subsubsection{Explaining $P U$}

Table 8 shows that Web security has a significant positive effect on PU (supporting Hypothesis 5c). This empirical study also found that PEOUT significantly and positively affects PU (supporting Hypothesis $4 \mathrm{~b}$ ). Accordingly, this regression model explained $13.9 \%$ of the variance in $\mathrm{PU}$ of e-shopping.

\subsubsection{Explaining PEOUT}

According to Table 9, PEOUW and US were found significantly and positively to affect PEOUT (supporting

Table 7

Regression results on explaining attitudes toward e-shopping

\begin{tabular}{lllll}
\hline $\begin{array}{l}\text { Dependent } \\
\text { variable }\end{array}$ & $\begin{array}{l}\text { Independent } \\
\text { variables }\end{array}$ & $\begin{array}{l}\text { Adjusted } \\
R^{2}\end{array}$ & $\beta_{\mathrm{S}}{ }^{\mathrm{a}}$ & $P$-value \\
\hline $\mathrm{A}$ & $\mathrm{S}$ & 0.313 & $0.211^{* * *}$ & 0.001 \\
& AC & & $-0.199^{* * *}$ & 0.001 \\
& PEOUW & & $-0.070^{* *}$ & 0.265 \\
& PEOUT & & $0.191^{* * *}$ & 0.004 \\
& PU & & $0.319^{* * *}$ & 0.000 \\
& US & & $0.194^{* *}$ & 0.002 \\
& PIQ & & 0.117 & 0.168 \\
& PSQ & & -0.010 & 0.900 \\
& PSvQ & & -0.060 & 0.441 \\
\hline
\end{tabular}

\footnotetext{
${ }^{\text {a }}$ Standardized $\beta$ coefficient.

*** 0.01 significance level.

****0.001 significance level.
} 
Table 8

Regression results on explaining PU

\begin{tabular}{lllrl}
\hline $\begin{array}{l}\text { Dependent } \\
\text { variable }\end{array}$ & $\begin{array}{l}\text { Independent } \\
\text { variables }\end{array}$ & $\begin{array}{l}\text { Adjusted } \\
R^{2}\end{array}$ & \multicolumn{1}{l}{$\beta_{\mathrm{S}}{ }^{\mathrm{a}}$} & $P$-value \\
\hline PU & S & 0.139 & $0.195^{* *}$ & 0.005 \\
& AC & & -0.023 & 0.734 \\
& PEOUW & & 0.093 & 0.182 \\
& PEOUT & & $0.230^{* *}$ & 0.002 \\
& US & & -0.004 & 0.958 \\
& PIQ & & 0.014 & 0.880 \\
& PSQ & & 0.150 & 0.106 \\
& PSvQ & & 0.001 & 0.989 \\
\hline
\end{tabular}

${ }^{\mathrm{a}}$ Standardized $\beta$ coefficient.

*** 0.01 significance level.

Table 9

Regression results on explaining PEOUT

\begin{tabular}{lllll}
\hline $\begin{array}{l}\text { Dependent } \\
\text { variable }\end{array}$ & $\begin{array}{l}\text { Independent } \\
\text { variables }\end{array}$ & $\begin{array}{l}\text { Adjusted } \\
R^{2}\end{array}$ & $\beta_{\mathrm{S}}{ }^{\mathrm{a}}$ & $P$-value \\
\hline PEOUT & S & 0.185 & 0.086 & 0.198 \\
& AC & & 0.051 & 0.444 \\
& PEOUW & & $0.299^{* * * *}$ & 0.000 \\
& US & & $0.199^{* * *}$ & 0.003 \\
& PIQ & & 0.079 & 0.392 \\
& PSQ & & 0.113 & 0.211 \\
& PSvQ & & -0.034 & 0.690 \\
\hline
\end{tabular}

\footnotetext{
${ }^{\text {a }}$ Standardized $\beta$ coefficient.

** 0.01 significance level.

**** 0.001 significance level.
}

Hypotheses $3 \mathrm{c}$ and $7 \mathrm{~b}$, respectively). The regression model explained $18.5 \%$ of the variance in PEOUT of e-shopping.

\subsubsection{Explaining PEOUW}

From Table 10, Web security and US significantly and positively affected PEOUW (supporting Hypo-

Table 10

Regression results on explaining PEOUW

\begin{tabular}{lllrl}
\hline $\begin{array}{l}\text { Dependent } \\
\text { variable }\end{array}$ & $\begin{array}{l}\text { Independent } \\
\text { variables }\end{array}$ & $\begin{array}{l}\text { Adjusted } \\
R^{2}\end{array}$ & $\beta_{\mathrm{S}}{ }^{\mathrm{a}}$ & $P$-value \\
\hline PEOUW & $\mathrm{S}$ & 0.053 & $0.167^{*}$ & 0.019 \\
& $\mathrm{AC}$ & & -0.002 & 0.972 \\
& $\mathrm{US}$ & & $0.192^{* *}$ & 0.005 \\
\hline
\end{tabular}

\footnotetext{
${ }^{a}$ Standardized $\beta$ coefficient.

* 0.05 significance level.

** 0.01 significance level.
}

theses $5 \mathrm{a}$ and $7 \mathrm{a}$, respectively). The regression model explained only $5.3 \%$ of the variance in PEOUW of e-shopping.

\subsubsection{Summary of results}

The significant standardized $\beta$ coefficients of the extended model are shown in Fig. 2. As theorized in the hypotheses, consumers have different acceptance regarding distinct types of products or services as well as different on-line offerings. In sum, Hypotheses 1a and $1 \mathrm{~b}$ were fully supported; Hypotheses $3 \mathrm{e}, 5 \mathrm{f}, 6 \mathrm{e}, 7 \mathrm{e}$, $7 \mathrm{f}, 8 \mathrm{~d}, 8 \mathrm{e}, 9 \mathrm{~d}$ and $10 \mathrm{~d}$ were partially supported. In contrast, Hypotheses 2b, 2c, 3a, 3b, 3d, 4c, 4d, 5b, 5e, 6a, 6b, 6c, 6f, 7c, 8a, 8b, 8c, 9a, 9b, 9c, 9e, 10a, 10b, $10 \mathrm{c}$ and $10 \mathrm{e}$ were not supported.

\section{Discussion}

This study suggests that user acceptance is a better indicator of e-shopping intentions than user satisfaction. In testing the extended model, we found that individual attitudes toward e-shopping significantly and positively affect user acceptance, confirming the theoretical postulation of TAM. Briefly, consumer attitudes toward e-shopping strongly determine their willingness to use the Internet/WWW to shop for physical or digital products or on-line services, or to place an order, request post-purchase service, take delivery and make a payment. We also confirmed that both PU and PEOUT determine consumer attitudes toward e-shopping. The results reveal that consumer perceptions of the ease and effectiveness of e-shopping may indirectly lead to consumer acceptance of e-shopping via their attitudes. The significant positive effect of PEOUT on the revised PU is also confirmed; this is consistent with TAM. As expected, the significant positive effect of PEOUW on PEOUT was validated. However, inconsistent with the proposition of TAM, this study did not find that the revised PU significantly affected user acceptance of e-shopping.

The empirical results show that Web security did not affect consumer willingness to shop for any types of products or services via the Internet. Among the processes involved in e-shopping, consumers were most concerned with Web security during the delivery and payment phases. The findings reveal that the 

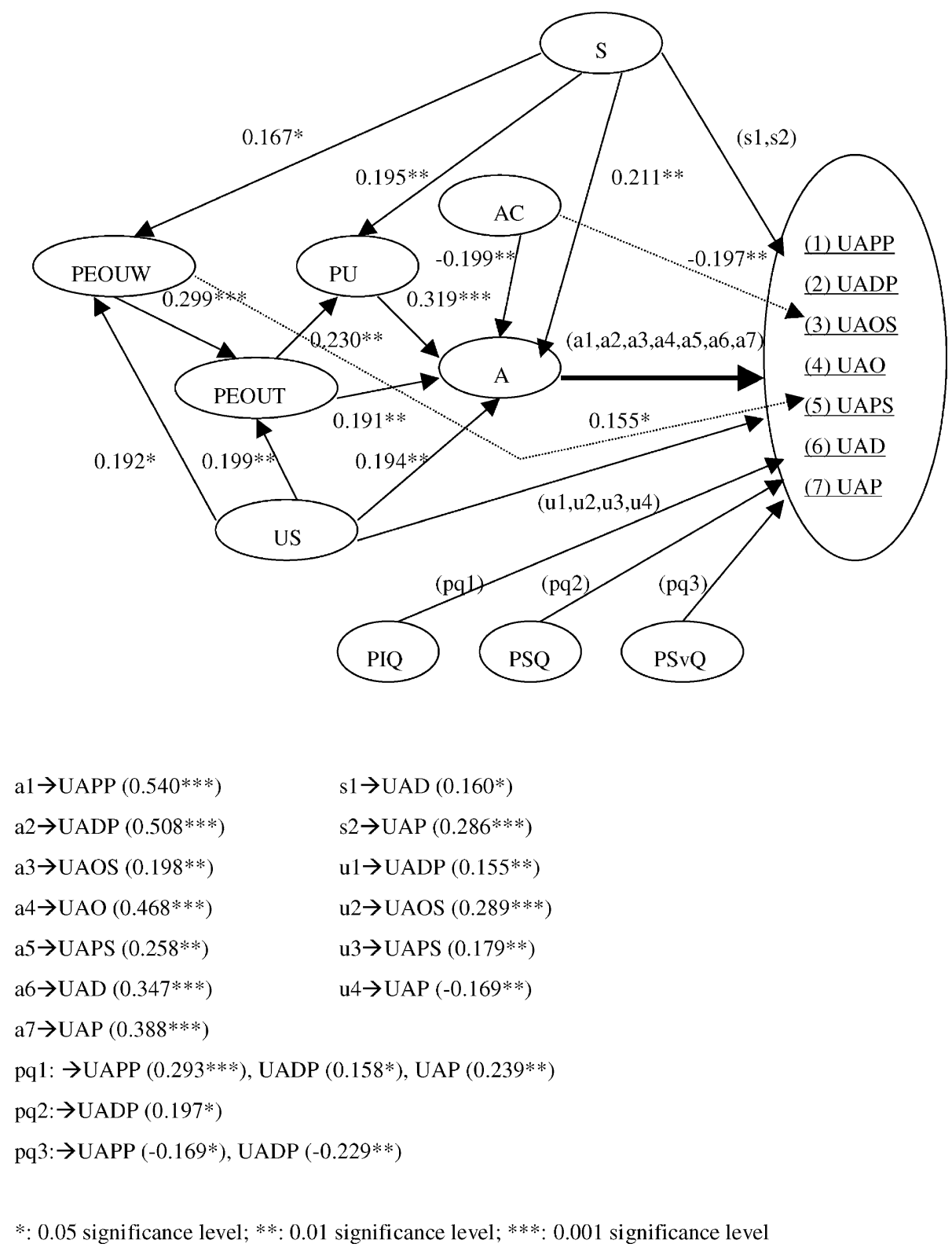

Fig. 2. Regression results with significant standardized $\beta$ coefficients.

Web-based security determine consumer willingness to download digital products and transfer money via the Internet. Generally, high Web security directly increased consumer attitudes toward e-shopping, or indirectly increased their attitudes by boosting their perceptions of the usefulness of e-shopping. As expected, high access costs would decrease consumer attitudes toward e-shopping, thus reducing their willingness to shop on-line services.

In the extended model, US determines PEOUW, PEOUT and the attitudes toward e-shopping. As a result, high user satisfaction with the Internet/WWW 
would increase consumer willingness to shop for digital products and on-line services, and to accept post-purchase services. Many Internet users rigorously assessed the effectiveness (or value) of e-shopping.

The empirical results imply that consumers who emphasize the importance of information quality prefer to shop for physical or digital products on the Web or pay on-line. Moreover, a reliable Web system that supports e-shopping functions could increase consumer intentions to shop for digital products. When consumers are concerned with service quality, they have low willingness to shop for physical or digital products on the Web.

The empirical findings presented in this study also provide helpful market strategies that e-stores can use to enhance consumer willingness to shop on-line. Our study thus suggests that providing consumers with secure Web systems or low access costs or increasing their perceptions of the usefulness and ease of on-line trading would indirectly improve their acceptance of e-shopping via creating positive attitudes. The unexpected negative effect of US on user acceptance of paying on-line reveals that most Internet users are worried about transferring money in the current Web system.

\section{Limitations}

The extended model should be interpreted carefully when applied to predict the e-shopping behavior of inexperienced Internet users, or extending the results to other consumers.

Only $33.5 \%$ of the respondents had e-shopping experience, which may lead to opposite cognitive impacts on assessing individual PU and PEOU of e-shopping between experienced and inexperienced consumers. This phenomenon is different from that of prior studies, which assessed the PU and PEOU from experienced IS/IT users. Basically, the model was used to predict respondent willingness (user acceptance) to shop on the Web via the theoretical determinants of IS/IT behavior in prior studies.

\section{Acknowledgements}

The author would like to thank the two anonymous reviewers for their valuable comments and suggestions that greatly enhanced the manuscript quality. Many thanks to the editor of Information and Management, Professor Sibley, for his editing support.

\section{Appendix A. Operationalization of the constructs associated with measures}

\section{Attitude (A)}
A1
A2
I feel that shopping on the Internet/WWW is interesting
I like to shop on the Internet/WWW

\section{Security (S)}

$\mathrm{S} 1$

S2

I feel that most e-stores are trustworthy

I trust current network security

3. Access costs (AC)

$\mathrm{AC} 1$

I accept the current costs of accessing the Internet/WWW

AC2

4. Perceived ease of use of the Web (PEOUW)

PEOUW1 I feel that most Web sites allow information to be easily accessed on-line

PEOUW2 I feel that most Web sites allow product/service information to be easily obtained

5. Perceived ease of use of trading on-line (PEOUT)

PEOUT1 I feel that most Web sites allow easy ordering on-line

PEOUT2 I feel that most Web sites allow delivery to be easily taken

PEOUT3 I feel that most Web sites allow easy payment 
6. Perceived usefulness (PU)

PU1 Trading on the Internet/WWW will save me time

PU2 Trading on the Internet/WWW will reduce my costs

7. User satisfaction (US) with the Internet/WWW

US1

US2

US3

The Internet/WWW enhances my quality of life

The Internet/WWW enhances my ability to learning

US4

The Internet/WWW enhances my job performance

The Internet/WWW enhances my domain knowledge

8. Perceived information quality (PIQ)

PIQ1

PIQ2

Accuracy of information will affect my decision to e-shop

PIQ3

PIQ4

Completeness of information will affect my decision to e-shop

PIQ5

Understandability of information will affect my decision to e-shop

Timeliness of information will affect my decision to e-shop

Availability of information will affect my decision to e-shop

9. Perceived system quality (PSQ)

PSQ1 The query supporting function of Web sites will affect my decision to e-shop

PSQ2 The functions of search engines will affect my decision to e-shop

PSQ3 The reliability of Web sites will affect my decision to e-shop

10. Perceived service quality (PSvQ)

PSvQ1 Delivery timing will affect my decision to e-shop

PSvQ2 Ease of returning merchandise will affect my decision to e-shop

PSvQ3 Ease of paying will affect my decision to e-shop

PSvQ4 Privacy protection will affect my decision to e-shop

11. User acceptance (UA)

UAPP (UA of physical products)

UADP (UA of digital products)

UAOS (UA of on-line services)

UAO (UA of ordering)

UAPS (UA of post-purchase services)

UAD (UA of delivery)

UAP (UA of payment)

I am willing to accept physical products obtained by e-shopping I am willing to accept digital products obtained by e-shopping

I am willing to accept on-line services obtained by e-shopping

I am willing to order on-line

I am willing to request post-purchase services on-line

I am willing to take delivery on-line

I am willing to pay on-line

The following measures were dropped in the model testing:

A3 I feel that e-shopping is fair for both consumers and firms

PEOUT4 I feel that most Web sites provide calculation functions on-line

PEOUT5 I feel that most Web sites allow services to be easily requested on-line

PU3 I will acquire real-time information through the Internet/WWW

PU4 Searching for products/services on the Internet/WWW is effective

PU5 Comparing the prices of products/services on the Internet/WWW is effective

US5 The Internet/WWW enhances my coordination and communication skills in teamwork

PSQ4 Network speed will affect my decision to e-shop 


\section{References}

[1] D.A. Adams, R.R. Nelson, P.A. Todd, Perceived usefulness, ease of use, and usage of information technology: a replication, MIS Quarterly 16 (2), 1992, pp. 227-247.

[2] I. Ajzen, From intentions to actions: a theory of planned behavior, in: J. Kuhl, J. Beckmann (Eds.), Action Control: From Cognition to Behavior, Springer, New York, 1985, pp. 11-39.

[3] I. Ajzen, Attitude structure and behavior, in: A.R. Pratkanis, S.J. Breckler, A.G. Greenwald (Eds.), Attitude Structure and Function, Lawrence Erlbaum, Hillsdale, NJ, 1989, pp. 241274.

[4] I. Ajzen, M. Fishbein, Understanding Attitudes and Predicting Social Behavior, Prentice-Hall, Englewood Cliffs, NJ, 1980.

[5] J.E. Bailey, S.W. Pearson, Development of a tool for measuring and analyzing computer user satisfaction, Management Science 29 (6), 1983, pp. 519-529.

[6] J.J. Baroudi, M.H. Olson, B. Ives, An empirical study of the impact of user involvement on system usage and information satisfaction, Communications of the ACM 29 (3), 1986, pp. 232-238.

[7] M.K. Chang, W. Cheung, Determinants of the intention to use Internet/WWW at work: a confirmatory study, Information and Management 39 (1), 2001, pp. 1-14.

[8] P.Y.K. Chau, An empirical assessment of a modified technology acceptance model, Journal of Management Information Systems 13 (2), 1996, pp. 185-204.

[9] F.D. Davis, A technology acceptance model for empirically testing new end-user information systems: theory and results, Doctoral Dissertation, Sloan School of Management, Massachusetts Institute of Technology, 1986.

[10] F.D. Davis, R.P. Bagozzi, P.R. Warshaw, User acceptance of computer technology: a comparison of two theoretical models, Management Science 35 (8), 1989, pp. 982-1003.

[11] F.D. Davis, Perceived usefulness, perceived ease of use, and user acceptance of information technology, MIS Quarterly 13 (3), 1989, pp. 319-339.

[12] F.D. Davis, User acceptance of information technology: system characteristics, user perceptions and behavioral impacts, International Journal of Man-Machine Studies 38 (3), 1993, pp. 475-487.

[13] M. Fishbein, I. Ajzen, Belief, Attitude, Intention, and Behavior, Addison-Wesley, Reading, MA, 1975.

[14] C. Fornell, D.F. Larcker, Evaluating structural equation models with unobservable variables and measurement error, Journal of Marketing Research 18 (1), 1981, pp. 39-50.

[15] C. Fornell, G. Tellis, G. Zinkhan, Validity assessment: a structural equations approach using partial least squares, in: Proceedings of the American Marketing Association Educator's Conference, Chicago, 1982, pp. 405-409.

[16] A.W. Gatian, Is user satisfaction a valid measure of effectiveness? Information and Management 26 (3), 1994, pp. 119-131.

[17] D. Gefen, M. Keil, The impact of developer responsiveness on perceptions of usefulness and ease of use: an extension of the technology acceptance model, DATA BASE 29 (2), 1998, pp. $35-49$.

[18] M. Gelderman, The relation between user satisfaction, usage of information systems and performance, Information and Management 34 (1), 1998, pp. 11-18.

[19] J.F. Hair, R.E. Anderson, R.L. Tatham, and W.C. Black, Multivariate Data Analysis with Readings, 4th ed., PrenticeHall, Englewood Cliffs, NJ, 1995.

[20] S. Hamilton, N. Chervany, Evaluating information system effectiveness. Part 1, Comparing evaluation approaches, MIS Quarterly 5 (3), 1981, pp. 55-69.

[21] D.L. Hoffman, T.P. Novak, A new marketing paradigm for electronic commerce, The Information Society 13 (1), 1997, pp. $43-54$.

[22] M. Igbaria, T. Guimaraes, G.B. Davis, Testing the determinants of microcomputer usage via a structural equation model, Journal of Management Information Systems 11 (4), 1995, pp. 87-114.

[23] M. Igbaria, M. Tan, The consequences of information technology acceptance on subsequent individual performance, Information and Management 32 (3), 1997, pp. 113-121.

[24] M. Igbaria, N. Zinatelli, P. Cragg, A.L.M. Cavaye, Personal computing acceptance factors in small firms: a structural equation model, MIS Quarterly 21 (3), 1997, pp. 279-302.

[25] J. Iivari, I. Ervasti, User information satisfaction: IS implementability and effectiveness, Information and Management 27 (4), 1994, pp. 205-220.

[26] S.L. Jarvenpaa, P.A. Todd, Consumer reactions to electronic shopping on the World Wide Web, International Journal of Electronic Commerce 1 (2), 1997, pp. 59-88.

[27] R.L. Keeney, The value of Internet commerce to the customer, Management Science 45 (4), 1999, pp. 533-542.

[28] W.J. Kettinger, C.C. Lee, Perceived service quality and user satisfaction with the information services function, Decision Sciences 25 (6), 1994, pp. 737-766.

[29] Z. Liao, M.T. Cheung, Internet-based e-shopping and consumer attitudes: an empirical study, Information and Management 38 (5), 2001, pp. 299-306.

[30] Z. Liao, M.T. Cheung, Internet-based e-banking and consumer attitudes: an empirical study, Information and Management 39 (4), 2002, pp. 283-295.

[31] C. Liu, K.P. Arnett, Exploring the factors associated with Web site success in the context of electronic commerce, Information and Management 38 (1), 2000, pp. 23-33.

[32] A. Mahmood, Systems development methods-a comparative investigation, MIS Quarterly 11 (3), 1987, pp. 293-311.

[33] K. Mathieson, Predicting user intentions: comparing the technology acceptance model with the theory of planned behavior, Information Systems Research 2 (3), 1991, pp. 173191.

[34] J. Miller, B.A. Doyle, Measuring effectiveness of computer based information systems in the financial services sector, MIS Quarterly 11 (1), 1987, pp. 107-124.

[35] M.A. Nour, A. Fadlalla, A framework for web marketing strategies, Information Systems Management (2000) 41-50.

[36] J. Nunnally, Psychometric Theory, McGraw-Hill, New York, 1967. 
[37] A. Parasuraman, V.A. Zeithaml, L.L. Berry, SERVQUAL: a multiple-item scale for measuring consumer perceptions of service quality, Journal of Retailing 64 (1), 1988, pp. 12-40.

[38] G. Paré, J.J. Elam, Discretionary use of personal computers by knowledge workers: testing of a social psychology theoretical model, Behavior and Information Technology 14 (4), 1995, pp. 215-228.

[39] L.F. Pitt, R.T. Watson, C.B. Kavan, Service quality: a measure of information systems effectiveness, MIS Quarterly 19 (2), 1995, pp. 173-187.

[40] A. Srinivasan, Alternative measures of system effectiveness: associations and implications, MIS Quarterly 9 (3), 1985, pp. 243-253.

[41] T.J. Strader, M.T. Shaw, Characteristics of electronic markets, Decision Support Systems 21 (3), 1997, pp. 185-198.

[42] E.B. Swanson, Management information systems: appreciation and involvement, Management Science 21 (2), 1974, pp. $178-188$.

[43] B. Szajna, Empirical evaluation of the revised technology acceptance model, Management Science 42 (1), 1996, pp. 8592.
[44] R.L. Thompson, C.A. Higgins, J.M. Howell, Influence of experience on personal computer utilization: testing a conceptual model, Journal of Management Information Systems 11 (1), 1994, pp. 167-187.

[45] H.C. Triandis, Values, attitudes, and interpersonal behavior, in: Proceedings of the Nebraska Symposium on Motivation, 1979: Beliefs, Attitudes, and Values, University of Nebraska Press, Lincoln, NE, 1980, pp. 195-259.

[46] V. Venkatesh, F.D. Davis, A theoretical extension of the technology acceptance model: four longitudinal field studies, Management Science 46 (2), 2000, pp. 186-204.

[47] R.T. Watson, L.F. Pitt, C.B. Kavan, Measuring information systems service quality: lessons from two longitudinal case studies, MIS Quarterly 22 (1), 1998, pp. 61-79.

Hung-Pin Shih is an Assistant Professor of Information Management Department at Hsuan Chuang University, Taiwan. He received his $\mathrm{PhD}$ from National Chiao Tung University in Taiwan. His research interests include electronic commerce and IS/IT adoption. 